\title{
Introduction by the Editorial Team
}

The COVID-19 crisis is having a serious and unprecedented impact on the world of work and thus it is no surprise that the ILO devotes many of its resources to identifying and addressing the main challenges. According to the concept note released in the framework of the July 2020 ILO Global Virtual Summit on COVID-19 and the World of Work, we are facing "the most serious human, economic and social crisis of modern times." The ILO estimates that a 10.7 percent reduction of the hours of work worldwide in the second quarter of 2020. This has led to hundreds of millions of additional lost jobs. Vulnerable and disadvantaged people have been hit hardest. Think, for instance, about people with precarious employment contracts or those working in the informal sector. Women are also disproportionately affected, given that they are overrepresented in sectors either more affected or in the front line of dealing with the pandemic, such as health and care services. The ILO estimates furthermore that approximately 436 million enterprises-mainly micro, small, and medium-sized ones - are at high risk.

To address these and other challenges, the ILO has developed a policy framework, based on international labor standards, that contains four pillars to fight the COVID-19 crisis. The first pillar deals with measures to stimulate the economy and employment. The second is about supporting enterprises, jobs and incomes by means of social protection, employment retention measures, and tax relief. The third deals with protection of workers in the workplace by strengthening health and safety measures, preventing discrimination and exclusion, and providing access to health. The fourth emphasizes that we should rely on social dialogue for solutions. This includes strengthening the capacity of workers' and employers' organizations and governments and strengthening social dialogue, collective bargaining and labor relations institutions. Respect for fundamental labor rights is essential in mitigating the effects of the COVID-19 crisis, which already leads to increased inequalities worldwide. This issue of ILaRC features cases and commentaries dealing with those core workers' rights that are increasingly under pressure.

Former ILO Legal Adviser Loïc Picard analyzes the ILO Committee of Experts' Observation on the situation of forced labor in Qatar. After years of constitutional proceedings - both the representation and complaint procedures were invoked - the Committee examines the way in which the government of 
Qatar, assisted by a technical cooperation program under the auspices of the Governing Body, has fulfilled its obligations under Convention No. 29 in relation to the treatment of migrant workers. Picard examines how the different supervisory mechanisms of the ILO have assisted in slowly but surely bringing the law and practice of Qatar in conformity with Convention No. 29. Although, he concedes, it is still too early to draw definite conclusions, it is clear that the ILO's constitutional procedures have led to a technical cooperation programme that addresses many of the challenges in relation to migrant workers in Qatar. Picard emphasizes that "Although, as it is often said, the ILO may not have teeth, it does have jaws that, once clenched, do not open easily."

Christian González Chacón, who serves as a human rights specialist with the cases section of the Inter-American Commission on Human Rights, describes the landmark decision of the Commission in "Former Employees of the Judiciary v. Guatemala" in which the Commission for the first time declared a violation of the right to strike under Article 26 of the American Convention on Human Rights. The case has been referred to the Inter-American Court of Human Rights for a binding judgment. The case concerns the dismissal of ninety-three employees of the judiciary of Guatemala for having participated in a strike action in 1996. The Commission determined that the State had violated the right to be heard, the right of defense, the right to judicial protection, and-most important for this commentary - the right to work of the employees. González Chacón explains how the Commission argues that under international law, the additional requirements in Guatemalan law posed a disproportionate restriction on the right to strike. He expresses his hope that this case will serve as a steppingstone that will allow "further development on the content, scope, and validity of restrictions on the right to strike of workers in the Inter-American human rights system."

As always, the editorial team welcomes suggestions from readers of cases to be included in later issues. Please email ilarc@hhs.nl. 